\title{
DIAGNOSIS OF THREE TYPES DAMAGES TO THE VENTILATION SYSTEM
}

\author{
Orest VOZNYAK ${ }^{1}$, Nadiia SPODYNIUK ${ }^{2}$, Iryna SUKHOLOVA ${ }^{1}$, Olena SAVCHENKO ${ }^{1}$, \\ Mariana KASYNETS ${ }^{1}$, Oleksandra DATSKO ${ }^{3}$ \\ ${ }^{1}$ Lviv Polytechnic National University, Department of Heat and Gas Supply and Ventilation \\ St. Bandery, 12, 79013, Lviv - 13, Ukraine, e-mail: orest.voznyak@i.ua \\ ${ }^{2}$ National University of Life and Environmental Sciences of Ukraine, \\ Department of Heat and Power Engineering, \\ Heroyiv Oborony Str., 12, 03041, Kyiv, Ukraine, e-mail: n_spoduniuk@meta.ua \\ ${ }^{3}$ Lviv Polytechnic National University, Department of Civil Safety \\ St. Bandery, 12, 79013, Lviv - 13, Ukraine, e-mail: dacko_lp@ukr.net,
}

\begin{abstract}
The article is devoted to solving of urgent problem to eliminate damage in ventilation system. That is caused by non-adequate long range, stagnant unventilated areas in the room existance and high noise level in the premises at air distribution by swirled air flow, compact air jet, flat air stream and rectangular air jet. A noise level of air supply with swirled air flow, compact air jet, flat air jet and rectangular air stream in the room has been investigated. It is shown that in order to achieve the maximum noise level decreasing it is necessary to ensure its supply by jets, which less intensively attenuate before entering the premise working area. Results of the experimental research are presented as graphical and analytical dependences. The acoustic properties of the swirled air flow, compact air jet, flat air stream and rectangular air jet have been investigated and means of situation improving have been determined. The results of experimental research of air supply to the room are presented. It is established that with the increase of the angle of swirling plates inclination and ratio of the slit sides the air jets noise level decreases.
\end{abstract}

Keywords: air distribution, air velocity, swirled air jet, compact air jet, flat air jet.

\section{Nomenclature}

$\alpha$ - angle of the twisting plate's inclination

$\zeta$ - coefficient of aerodynamic resistance

$\psi$ - additional function

$c$ - experimental constant

$d, D$ - diameter of the air distributor with the twisting plates, $\mathrm{mm}$

$b$ - height of the slit, $\mathrm{m}$

$F_{0}$ - the area of openings, $\mathrm{m}^{2}$

$l$ - length of the slit, $\mathrm{m}$

$L$ - air flow rate, $\mathrm{m}^{3} / \mathrm{h}$

$\bar{L}-$ sizeless aerodynamic noise level

$m$ - velocity attenuation coefficient

$n$ - exponent

$v$ - velocity, $\mathrm{m} / \mathrm{s}$,

$x$ - running coordinate, $\mathrm{m}$

$$
\begin{aligned}
& \text { Subscripts } \\
& 0-\text { initial } \\
& \text { max - maximal } \\
& r-\text { rectangular } \\
& x-\text { current } \\
& s-\text { swirled }
\end{aligned}
$$

\section{INTRODUCTION}

The human physiological needs $[13,14]$ and the effectiveness of human work depends largely on the indoor climate [12]. Important problems of room ventilation are to ensure both effective organization of air exchange and air distribution [10]. So, the requirements of ensuring of the normalized air velocity and temperature in the premise working area $[4,13,14]$ and energy efficiency $[1,28,38,41]$ should be followed. Heat utilization of exhaust air by recuperators $[2,7,37]$ is often used. It is obvious that creation of a dynamic indoor climate is also advisable in the closed spaces [20, 38]. It means periodic change of air temperature or air velocity in the working area of the room.

Sometimes the production process is taken place in small-sized premises, overloaded with technological equipment and personnel [39]. In this case the compressed conditions for air jet are created in these premises. There is a need to supply a large amount of tidal air. This usually makes it impossible to provide a normalized air velocity in the premise working area [17, 24, 32, 33]. The air stream velocity often exceeds the normalized values. As a result, it

(C) 2022 by the Authors. Licensee Polish Society of Technical Diagnostics (Warsow. Poland). This article is an open access article distributed under the terms and conditions of the Creative Commons Attribution (CC BY) license http://creativecommons.org/licenses/by/4.0/). 
does not provide effective attenuation of the air flow velocity [8]. The quantitative characteristic of the air stream velocity attenuation is corresponding attenuation coefficient $m$. It is known [8, 27], that decrease of air velocity attenuation coefficient is a desirable factor. It demands of intensive turbulence of air flow and results in increase of aerodynamic local resistance $[9,10,30,40]$. If the velocity attenuation coefficient $m$ is high, it indicates insufficient stream turbulence and a significant advantage of dynamic forces over friction ones. The velocity attenuation is directly related to air jet long range [31]. When the air jet long range becomes too high it needs to be reduced, because the conditions of comfort are violated [21]. This phenomenon means that the ventilation system has a damage type $1[31]$.

For this purpose the air distribution devices are proposed which provide a high intensity of the air velocity attenuation of the inflow stream with the formation of a swirled air jet [35]. This is a round shape of air jet. Another suitable one is rectangular shape of air jet: a flat, compact or rectangular one [31].

There is opposite problem, connected with insufficient air velocity attenuation coefficient. As a result stagnant unventilated areas in the room are formed due to insufficient air jets long-range [31]. Air distribution devices have a high coefficient of aerodynamic resistance $\zeta$ and the ventilation system becomes energy consuming [18, 22]. Thus, the air stream long range becomes too low and needs to be increased [31]. This results in to an excessive $\mathrm{CO}_{2}$ concentration in the premise $[5,12]$. This is damage type 2 to the ventilation system [31,34].

An adequate choice of air distribution devices [3, $20,35]$ with the appropriate coefficient of air jet velocity attenuation and also achieving proper air jet long range in a premise is mean for overcoming damage to the ventilation system of both types.

All proposed air jets (swirled, compact, flat, rectangular) have positive aerodynamic characteristics. But it is important question concerning acoustic properties of these air jets, namely noise level at its leakage. Excessive noise level means that the ventilation system has a damage type 3 . The noise appearance at jet's leakage from air distributors [31, 36] is necessary to take into account in designing ventilation or air conditioning system $[17,33]$. Noise generation at air jet's flowing out from outlet depends on its constructive realization and air jet stream velocity. The noise level is very important under leakage from the air distributor, when ventilation or air conditioning systems in premise is designed. Creation of noise by air-forming nozzles depends on its design performance and the air flow rate. There are known acoustic characteristics of the different air distributors [19, 36]. However, it is necessary to investigate noise level of proposed swirled and rectangular air jets at the different initial conditions.
Because of noise influences on the environment [36], solution of this problem is very significant.

Analysis of literary data has shown that a comfortable state of a person in a premise depends on many factors: air temperature [4, 24], air velocity [13], humidity, temperature of the premise surfaces, noise level, thermal resistance of clothing, concentration of $\mathrm{CO}_{2}$ in the premise $[15,16]$, etc. Air distribution schemes are considered and analyzed for being most appropriate to be used indoors, taking into account first of all the attenuation of inflow air jets $[6,26,29]$. It is substantiated that the most efficiency can be achieved using swirled air jets [37], that can leakage from the air distributor at the different angles of the twisting plates inclination [38], as well rectangular air jets at different ratio slit sizes (length and height). This ratio means flat, compact and rectangular air jet.

There are suitable mathematical models [21 - 23] so that to create an adequate hypothesis and to answer the questions: which are acoustic characteristics of the air jet at these conditions, which is a noise level created, air velocity attenuation coefficient and an aerodynamic local resistance coefficient?

Ensuring comfort conditions in premise and achieving energy efficiency of air distribution is possible due to elimination of damages of three types. This should be realised by optimizing the attenuation coefficient of air velocity, long range and also noise level by using of compact, flat, rectangular and swirled air jets.

\section{GOAL OF THIS PAPER}

The aim of the work is to eliminate damages of three types in ventilation systems due to: investigation of swirled air jet at the different angles of the twisting plates inclination; research of rectangular air jets at the different ratio slit sizes (length and height), that means flat, compact and rectangular air jet; analytical dependencies obtaining for characteristics determination of the all proposed air flows; dependency determination of air velocity attenuation coefficient, aerodynamic local resistance coefficient and noise level from the angle of the twisting plates inclination for swirled air jet and from ratio slit sizes for rectangular ones; optimization of the twisting plates inclination angle for swirled air jet and ratio slit sizes for rectangular ones.

To achieve the goal, it should be to carry out the the following research tasks:

- to analyze the characteristics of rectangular, flat, compact and swirled air jets, their efficiency and dependencies for calculation;

- to generalize and deepen the theory of aerodynamic processes in air supply by flat, compact, rectangular and swirled jet streams;

- to perform theoretical and experimental research of air distribution by rectangular, flat, compact and swirled air streams; 
- to establish graphical and analytical dependences for determination of the air velocity attenuation coefficient, aerodynamic local resistance coefficient and noise level from the angle of the twisting plates inclination for swirled air jet and from ratio slit sizes for rectangular ones.

\section{RESEARCH OF THE SWIRLED, FLAT, COMPACT AND RECTANGULAR AIR JET NOISE LEVEL AT IT LEAKAGE}

This work is continuing of air distribution research [31]: the air distributor (Fig.1 a) creates swirled air jet and devices (Fig.1 b, c, d) - compact, rectangular and flat air jets. In application of all devices (Fig.1) the variation of the flow rate is provided. In case of device (Fig.1a) variation of the twisting plates angle inclination was provided, but in case of devices (Fig.1 b, c, d) - of the ratio slit sizes (length and height).

It is necessary to carry out experimental studies and to establish numerical dependency of air

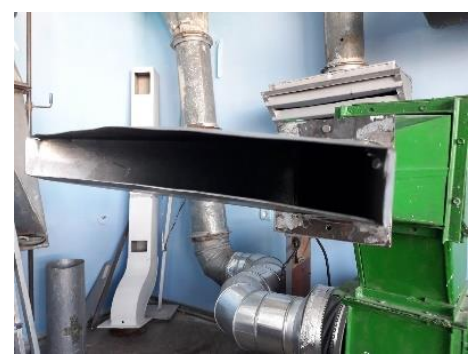

a)

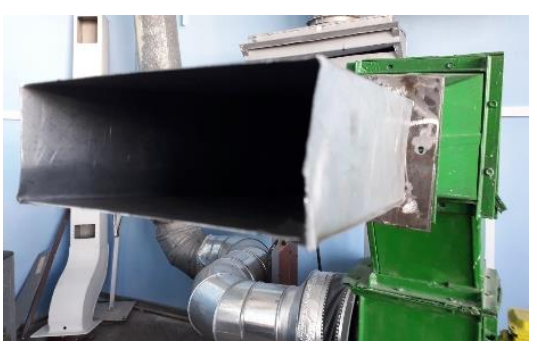

c) velocity attenuation coefficient, aerodynamic local resistance coefficient and noise level from the angle of the twisting plate's inclination for the swirled air jet and from the ratio slit sizes for the rectangular air jet.

It is known, that flat [9], compact [37, 38] and swirled $[35,37,38]$ air streams are ones of the most popular in ventilation technology. As we know, flat and compact air jets are usually used as horizontal, and swirled - as vertical [37, 38]. However, rectangular air jets were not considered, their research was started only in [31]. The reason is particular ratio slit sizes, namely length to height. In case of flat air jets tidal slit has a ratio of length to height $l / b \geq 10$, and with a ratio of $1<l / b<10$ it is expedient to call jets rectangular [31]. Hole's shape for compact air flows is round or square. If there are plates (Fig.1 a) in the cylindrical hole that can be deviated by a certain angle $\alpha$, then the swirled air jets are created. The twisting factor determines the special properties and aerodynamic characteristics of swirled air jets. As a result, they have different

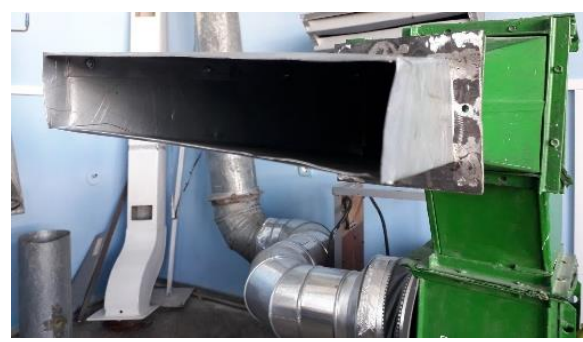

b)

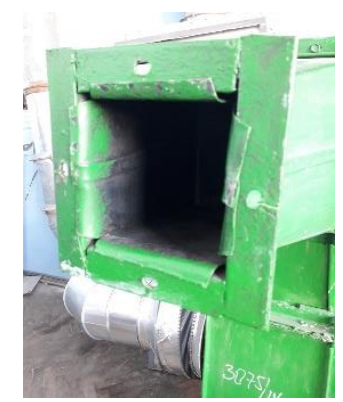

d)

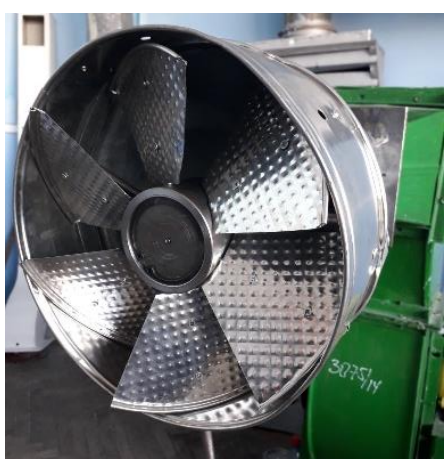

e)

Fig. 1. Experimental installation: a $)$ - slit with the ratio of the sides $l / b=10(300 \times 30 \mathrm{~mm})$ for a flat air jet b) - slit with the ratio of the sides $l / b=2.5(225 \times 45 \mathrm{~mm})$ for a rectangular air jet; c) - slit with the ratio of the sides $l / b=2.5(150 \times 60$ $\mathrm{mm}$ ) for a rectangular air jet; d) - slit with the ratio of the sides $l / b=1(100 \times 100 \mathrm{~mm})$ for a compact air jet; e) - air distributor $D=250 \mathrm{~mm}$ with the twisting plates for a swirled air jet 
coefficients of air velocity attenuation and aerodynamic resistance, different acoustic properties of aerodynamic noise [36] depending from the twisting plates angle inclination. In particular, it would be interesting to compare the aerodynamic noise of flat, compact and rectangular air jets depending on the ratio of the sides of the supply slit $l / b$ and swirled air stream depending on the angle of the twisting plate's inclination $\alpha$.

As hypothesis we can assert that the aerodynamic noise of air jets is directly affected by the air velocity attenuation coefficient, which depends on the air distributor aerodynamic resistance. As we know [31], the flat air jet has the highest aerodynamic resistance and the compact air jet - the lowest. Due to sudden narrowing the aerodynamic resistance coefficient is higher and velocity attenuation coefficient is lower [25], which results in to the air jet noise level increase. Obviously, it is necessary to take into account the initial air jet velocity and the size of the tidal nozzle to determine the aerodynamic noise level. The aerodynamic resistance coefficient of the swirled air jet depends on the angle of the twisting plates inclination.

Due to self-similarity property, the hypothesis may be proposed: because of at smaller angles of the plate's inclination more intense turbulence of the swirled air jet is observed, so the attenuation coefficient of velocity decreases and both the resistance and noise level increases. So does rectangular air flows, because of angles of the plates inclination for the swirled air stream are similar to the ratio slit sizes for the rectangular air jet. Thus at smaller ratio slit sizes $b / l$ more intense turbulence of the rectangular air jet is observed, so the attenuation coefficient of velocity decreases and both the resistance and noise level increases.

This paper presents a generalization of the analytical dependencies for determining the aerodynamic noise level $L$ of the flat, compact, rectangular and swirled air jets and bringing them to a universal form. It should be noted that aerodynamic noise level for the universality must be presented in sizeless form.

For the convenience of the graphic image and analytical approximation, the ratio of the sides dimensions of the flat slit is presented in the form $b / l$ instead of $l / b$.

Taking into account the hypothesis, we assume the dependence (1) to determine the sizeless aerodynamic noise level of the flat, compact and rectangular air jets:

$$
\bar{L}=1-c\left(\frac{b}{l}\right)^{n}
$$

where:

$\bar{L}-$ sizeless aerodynamic noise level as relation current noise level $L$ to maximal $L_{\max }$;

$b$ and $l$-accordingly height and length of a tidal slit, $\mathrm{m}$;

$c$ - experimental constant, which depends on the ratio of the length of the tidal slit to its height $l / b$; $n$ - exponent.

Due to self-similarity property for the convenience of the graphic image and analytical approximation, equation for the swirled air jet is presented in the form (2):

$$
\bar{L}=1-c \alpha^{n}
$$

Where:

$\bar{L}$ - sizeless aerodynamic noise level as relation current noise level $L$ to maximal $L_{\max }$;

$\alpha-$ the angle of the twisting plates inclination, degree;

$c$-experimental constant;

$n$ - exponent.

The experimental investigations of the air distribution by both swirled and rectangular air jets have been carried out on the installation shown in Fig.1 under such conditions and simplifications:

- all air jets were isothermal;

- air flow rate was within: $L=100-500 \mathrm{~m}^{3} / \mathrm{h}$.

- angles of the twisting plates inclination: $15^{\circ}$, $30^{\circ}, 45^{\circ}, 60^{\circ}, 75^{\circ}, 90^{\circ}$;

- the initial velocity of air in nozzles for supply was in the range of: $v_{0}=2-6 \mathrm{~m} / \mathrm{s}$.

- the area of openings $F_{0}=0.009-0.010 \mathrm{~m}^{2}$;

- the ratio of the sides of the tidal slit: $l / b=10 ; 5$; 2.5; 1 ;

- diameter of the air distributor with the twisting plates: $d=150 \mathrm{~mm}, D=250 \mathrm{~mm}$.

Air velocity has been measured by thermal electrical anemometer Testo-405 using a coordinate system with a grid of points $5 \times 5 \mathrm{~cm}$. Due to measured initial and current air velocities it has been determined air velocity attenuation coefficient $m$ from equation (3):

$$
m=\frac{v_{x} x}{v_{0} \sqrt{F_{0}}}
$$

Where:

$m$ - air velocity attenuation coefficient;

$v_{0}, v_{x}-$ initial and current air velocity, $\mathrm{m} / \mathrm{s}$;

$x$ - running coordinate, $\mathrm{m}$;

$F_{0}$ - air outlet space area, $\mathrm{m}^{2}$.

Noise level has been measured by the UNI-T UT-352 noise level meter. The results of acoustic properties investigations are presented in Fig. 2.

This graph shows dependence of all air jets leakage noise level: for swirled air jet - from angle of air distributor twisting plates inclination and for all other air jets - from the ratio $b / l$ of the height $b$ to length $l$ of the tidal hole.

This graph (Fig. 2) is approximated by equations for determining of the sizeless noise level $\bar{L}$ depending from the angle of inclination $\alpha$ (4) of the twisting plates and from slit sizes ratio $b / l(5)$ :

$$
\begin{aligned}
& \bar{L}=1-0.03 \alpha^{0.5} \\
& \bar{L}=1-0.32\left(\frac{b}{l}\right)^{0.5}
\end{aligned}
$$




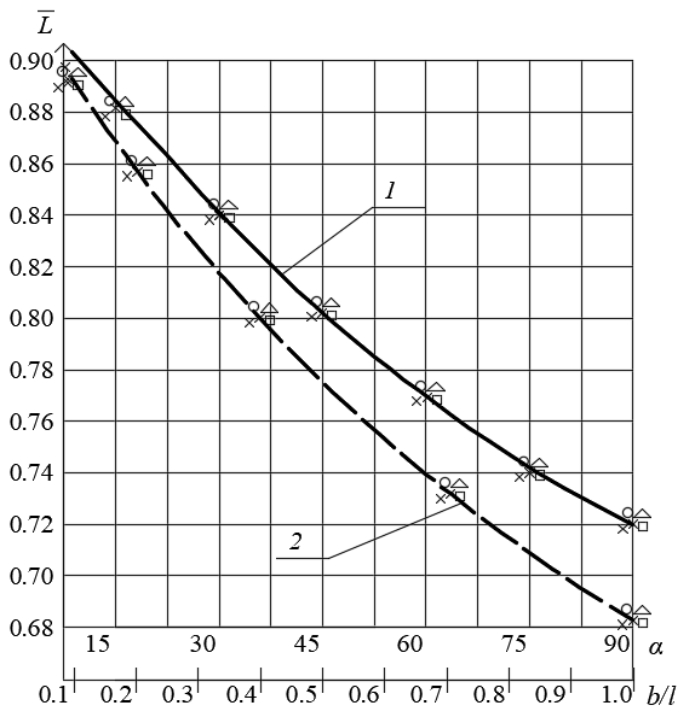

Fig. 2. Chart of the sizeless noise level $\bar{L}$ dependencies: 1 - from the angle $\alpha$ of the twisting plates inclination for the swirled air jet; 2 - from slit sizes ratio $b / l$ for the rectangular, flat and compact ones

Because of lines on Fig. 2 are very close, it confirms self-similarity and universality properties as well this data it is more convenient to present in Table 1.

Table 1

Sizeless noise level $\bar{L}$ dependence from the angle $\alpha$ of the twisting plates inclination for the swirled air jet and from slit sizes ratio $b / l$ for the rectangular, flat and compact ones

\begin{tabular}{cccccccccc}
\hline$\alpha$ & $9^{\circ}$ & $15^{\circ}$ & $18^{\circ}$ & $30^{\circ}$ & $36^{\circ}$ & $45^{\circ}$ & $60^{\circ}$ & $75^{\circ}$ & $90^{\circ}$ \\
\hline $\bar{L}$ & 0.91 & 0.89 & 0.87 & 0.84 & 0.82 & 0.8 & 0.77 & 0.74 & 0.72 \\
\hline$b / l$ & 0.10 & 0.16 & 0.20 & 0.33 & 0.40 & 0.50 & 0.66 & 0.84 & 1.0 \\
\hline $\bar{L}$ & 0.90 & 0.87 & 0.85 & 0.82 & 0.80 & 0.77 & 0.74 & 0.71 & 0.68 \\
\hline
\end{tabular}

Let us make some explanations to the table 1 . Since the equations for calculating jets of different types have been reduced to an universal form, the numerical values of the arguments must meet this requirement. The table shows the equality of the ratio of the current value to the maximum for both the angle $\alpha$ and for $b / l$, for example $9^{0} / 90^{\circ}=0.10 / 1.0$.

As it is known [25], in order to provide normative values of air velocity in the working area it should be reduced the velocity attenuation coefficient $m$. This is achieved by decreasing of the twisting plates angle for the swirled air jet and the slit sizes ratio $b / l$ for the rectangular flow. But at the same time it significantly increases both devices aerodynamic resistance and the aerodynamic noise level. Based on the experimental results, graphs (Fig. 3) are designed.

In Fig. 3 the research results of velocity attenuation coefficient $m$ and an air distributor aerodynamic local resistance coefficient $\zeta$ of all air distributors depending from the angle $\alpha$ of the twisting plates inclination for swirled air jet and from the slit sizes ratio $b / l$ for the rectangular, compact and flat air jets are presented. Velocity attenuation coefficient $m$ is presented in the left ordinate axis and aerodynamic local resistance coefficient $\zeta$ of an air distributors - in the right axis. All these graphs (Fig.3) are approximated by equations (6), (7), (8) and (9) for determining of the attenuation coefficients $m$ depending from the angle $\alpha$ of the twisting plates inclination for swirled air jet (6) and from the slit sizes ratio $b / l$ for all types of rectangular air jets, including flat and compact ones (7):

$$
\begin{aligned}
& m_{s}=0.02 \cdot \alpha-0.24 \\
& m_{r}=0.6+\frac{b}{l}
\end{aligned}
$$

and for determation of the aerodynamic local resistance coefficient $\zeta$ of the air distributor hyperbolic equation (8) for swirled air jet and (9) for all types of rectangular air jets:

$$
\begin{aligned}
& \zeta_{s}=\frac{22.5}{\alpha} \\
& \zeta_{r}=0.3\left(\frac{l}{b}\right)^{0.5}
\end{aligned}
$$

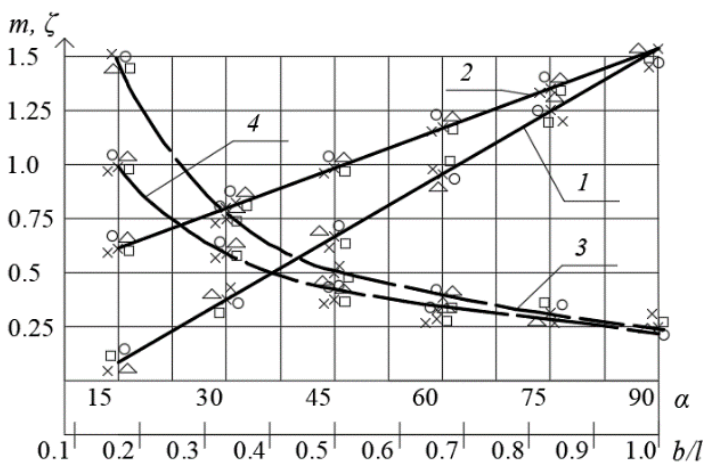

Fig. 3. Graphic dependencies from the twisting plates inclination angle $\alpha$ for the swirled air jet and from the slit sizes ratio $b / l$ for the rectangular ones

Solid lines - velocity attenuation coefficient $m$ :

1) - for the swirled air jet; 2) - for the rectangular air jet. Dotted lines - coefficient of local resistance $\zeta$ :

3) - for the swirled air jet; 4) - for the rectangular air jet

Consequently, in terms of velocity attenuation, it is effective to use the device at smaller angles of the twisting plates for swirled air jet and smaller slit sizes ratio $b / l$ for all types of rectangular air jets, where the velocity attenuation coefficient is minimal. But at the same time, in terms of aerodynamic resistance and the noise level, the situation is completely opposite. Therefore, it is quite logical to see the optimization problem of determining the optimal angle of inclination of the twisting plates for swirled air jet and optimal ratio slit sizes (length and height) for the rectangular air jets. This would satisfy the appropriate requirements, such as the velocity attenuation $m$ of the air jet (material content of the system), the 
aerodynamic resistance $\zeta$ (energy intensity of the system) and the noise level (acoustic properties).

To solve this problem, it is proposed to introduce an additional function $\psi$ depending on angle $\alpha$, which combines these values and represents their sum: $\psi(\alpha)=m(\alpha)+\zeta(\alpha)+\bar{L}(\alpha)$. This representation is correct, since all of these quantities are sizeless, depend on the same argument - the angle $\alpha$ of the twisting plates inclination for the swirled air jet and the slit sizes ratio $b / l$ for all types of rectangular air jets and are given by analytical expressions (10) and (11).

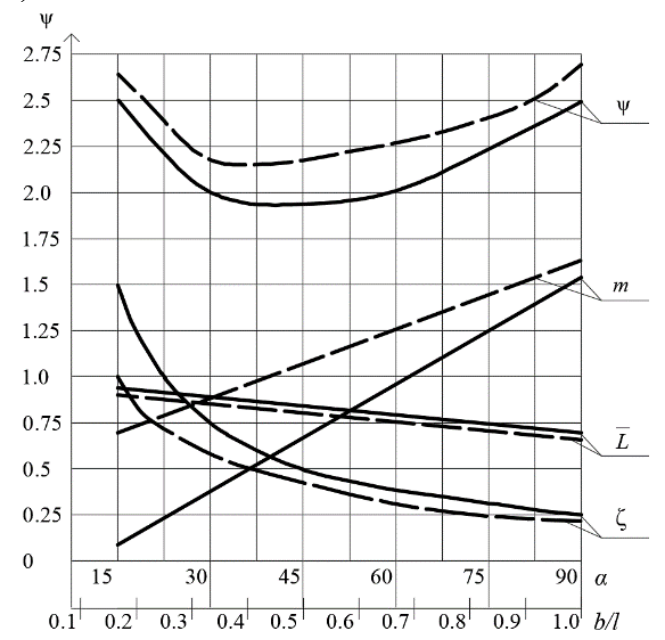

Fig. 4. Graph for determining of the twisting plates inclination optimal angle $\alpha$ (solid lines) and optimal slit

sizes ratio $b / l$ (dottled lines) taking into account all characteristics: attenuation, noise level and resistance

Graphically, it is presented in Fig.4. In analytical form - in expression (10) and (11) accordingly for the swirled air jet and for all types of rectangular air jets, including flat and compact:

$$
\begin{gathered}
\psi_{s}=0.02-0.24+\frac{22.5}{\alpha}+1-0.03 \cdot \alpha^{0.5} \\
\psi_{r}=1.6+\frac{b}{l}+0.3\left(\frac{l}{b}\right)^{0.5}-0.32 \cdot\left(\frac{b}{l}\right)^{0.5}
\end{gathered}
$$

Along with the graphical method of determining the optimal angle of inclination also the analytical method has been applied. To do this, we differentiate the expressions (10) and (11), equate the derivative to zero, and obtain the equation (12) and (13), which are unreasonable to solve by an algebraic method.

$$
\begin{aligned}
0.02 \alpha^{2}-0.015 \alpha^{1.5}-22.5 & =0 \\
\left(\frac{b}{l}\right)^{1.5}-0.15-0.16 \frac{b}{l}=0 &
\end{aligned}
$$

Instead, an iteration method is proposed, for which we obtain the solution $\alpha_{0}=36^{\circ}$ for the swirled air jet and $b / l=0.35$ for all types of rectangular air jets. Consequently, we obtain graphically $\alpha_{0}=35^{\circ}$ and analytically $\alpha_{0}=36^{\circ}$ for the swirled air jet and accordingly $b / l=0.35$ and $b / l=0.35$ (that are exactly the same) for the rectangular air jets.

So, the results are completely acceptable and confirm both self-similarity property of different types air flows and adequacy of analytical equations universality.

To determine the aerodynamic noise level of tidal air jets was implemented planning a complete three-factor experiment - Table 2, where the determining factors are:

$x_{l}=v_{0}-$ initial air jet velocity, $x_{l}=2-6 \mathrm{~m} / \mathrm{s}$;

$x_{2}=\alpha-$ the angle of the swirling plates inclination,

$$
x_{2}=15^{\circ}-75^{\circ} \text {; }
$$

$x_{3}=D-$ nozzle diameter, $x_{3}=150-250 \mathrm{~mm}$.

The optimization parameter is the air jet sizeless noise level $\bar{L}$. The linear mathematical model has been assumed.

Table 2

Planning matrix of a complete 3 -factor experiment

\begin{tabular}{cccccc}
\hline No & $x_{0}$ & $x_{1}=v_{0}$ & $x_{2}=\alpha$ & $x_{3}=D$ & $y=\bar{L}$ \\
\hline 1 & + & - & - & - & 0.70 \\
\hline 2 & + & + & - & - & 0,80 \\
\hline 3 & + & - & + & - & 0.73 \\
\hline 4 & + & + & + & - & 0.88 \\
\hline 5 & + & - & - & + & 0.75 \\
\hline 6 & + & + & - & + & 0.92 \\
\hline 7 & + & - & + & + & 0.78 \\
\hline 8 & + & + & + & + & 1.00 \\
\hline
\end{tabular}

According to the results of experiment planning, we obtain the regression equation (14):

$$
y=0.82+0.08 x_{1}+0.03 x_{2}+0.04 x_{3}
$$

The regression analysis showed that the noise level effect is most affected by the initial air velocity, and the least affected by the angle of the swirling plates inclination. Noise level increases with increasing all the determining factors: the initial air velocity, the angle of the swirling plates inclination and the diameter of the nozzle.

According to the experimental results a nomogram was created (Fig. 5).

Due to graphical dependence (Fig. 5) the direct problem and three inverse problems are solved (the corresponding solution keys are presented in Fig. 5). This means that any value from the four ones (the initial velocity $v_{0}$, the angle $\alpha$ of the twisting plates inclination, the diameter $D$ of the nozzle and the air jet noise level $L$ ) is determined if other three are given. This graph (Fig. 5) makes it possible to determine the required aerodynamic noise level of the swirled air jet to eliminate damage of the third type in the ventilation system.

For compact, flat and rectangular air jets, a similar experiment planning matrix is composed with the following determining factors:

$x_{1}=v_{0}-$ initial velocity of the air jet, $x_{1}=2-6 \mathrm{~m} / \mathrm{s}$; $x_{2}=b / l-$ the ratio of the slit height to its length, $x_{2}$ $=0.1-1$;

$x_{3}=b-$ slit height, $x_{3}=0.03-0.10 \mathrm{~m}$. 


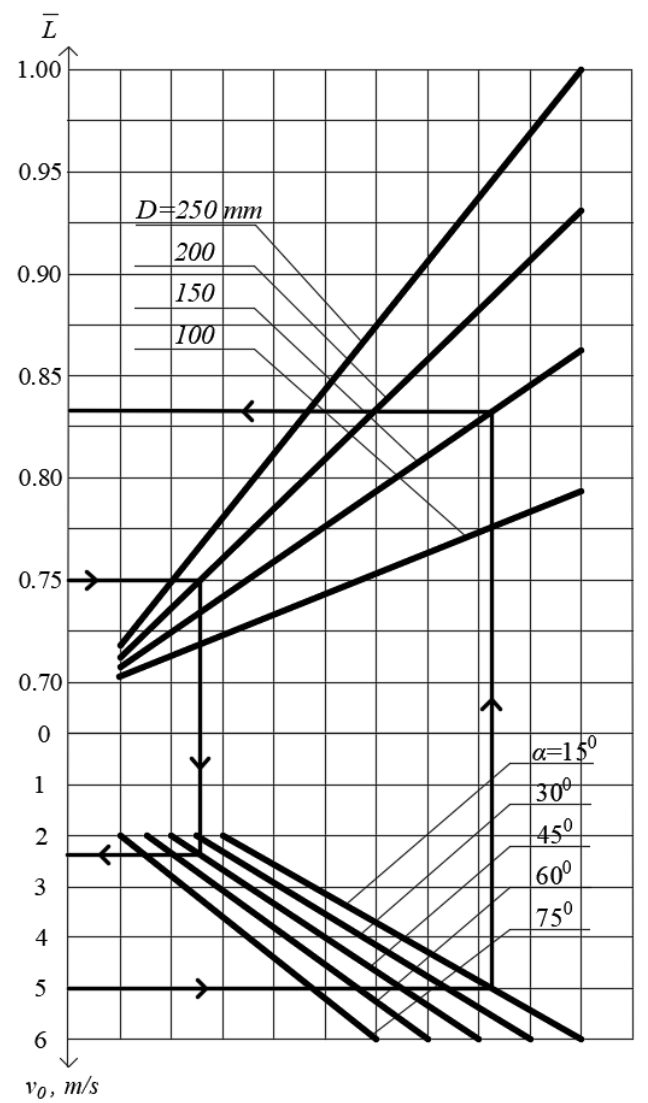

Fig. 5. Interdependence between aerodynamic sizeless noise level $L$, initial velocity $v_{0}$, angle of inclination $\alpha$ and nozzle diameter $D$

However, the non-linear mathematical model has been assumed. Interaction of the factors has been taken into account.

According to the results of experiment planning, it was received the regression equation (15) for the aerodynamic noise level as an optimization parameter:

$$
y=0.81+0.1 x_{1}-0.02 x_{2}+0.06 x_{3}+0.01 x_{2} x_{3}
$$

Only the coefficient that takes into account the interaction of factors $x_{2}$ and $x_{3}$ is significant, and the other regression coefficients are insignificant and are neglected.

The regression analysis showed that the smallest effect on the aerodynamic noise level is the ratio of the sides $b / l$ of the tidal slit, and the effect of the initial velocity is the most. However, the interaction of such factors as slit height $b$ and the ratio of the sides $b / l$ of the tidal slit is significant and should have been taken into account. The aerodynamic noise level increases with increasing initial velocity and slit height, but decreases with increasing ratio of slit height to its length $b / l$.

According to the results of the experiment, a nomogram was created (Fig. 6).

Similarly, to Fig. 5 due to graphical dependence (Fig. 6) four problems are solved (direct problem and three inverse problems). The corresponding solution keys are presented in Fig.6. This nomogram (Fig. 6) makes it possible to determine the required aerodynamic sizeless noise level of all types of rectangular air jet to eliminate damage of the third type in the ventilation system.

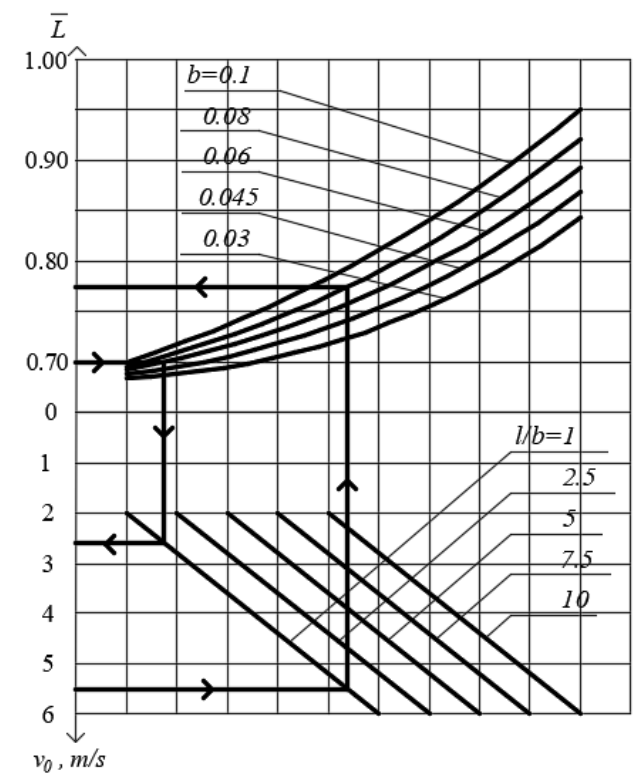

Fig. 6. Interdependence between aerodynamic sizeless noise level $L$, initial velocity $v_{0}$, ratio $l / b$ and tidal slit height $b$

\section{CONCLUSIONS}

1. On the basis of the conducted research graphic and analytical dependencies for determination of the aerodynamic noise level $L$ of all types of rectangular air jets (including flat and compact ones) and swirled air streams have been received and they are brought to a universal form. The ability to control the aerodynamic noise level of all air jets allows us to eliminate damage type 3 to the ventilation systems.

2. Graphical and analytical dependences for determination of air velocities of the rectangular, flat, compact, and swirled tidal air jets under the condition of creating a comfortable microclimate indoors are obtained. This eliminates type 3 damage to the ventilation or air conditioning system.

3. The hypothesis of the aerodynamic noise level of the flat, compact, rectangular and swirled air jets is experimentally confirmed.

4. The regression analysis showed that the noise level of the swirled air jets is most affected by the initial velocity, and the least affected by the angle of the swirling plates inclination. The noise level increases with increasing all the determining factors: the initial air velocity, the angle of the swirling plates inclination and the diameter of the nozzle. The smallest effect on the aerodynamic noise level is the ratio of the sides $b / l$ of the tidal slit, and the effect of the initial velocity is the most. The interaction of such factors as slit height $b$ and the ratio of the sides $b / l$ of the tidal slit is significant and should 
have been taken into account. The aerodynamic noise level increases with increasing initial velocity and slit height, but decreases with increasing ratio of slit height to its length $b / l$. These results make it possible to eliminate damage of the third type in ventilation systems.

5. The graphical way of the decision of four problems (direct and three inverse) in the form of the corresponding keys of the decision for the swirled, flat, compact and rectangular air streams is presented.

6. Application of the proposed air distribution devices substantially increases the quality of air distribution for supplying a significant amount of air into small-scale premises.

7. It is possible to carry out control of air distribution selection taking into account limited noise level based on the obtained dependencies.

8. It should be noted that the aerodynamic local resistance coefficient and aerodynamic noise level are the highest at angle of twisting plates $\alpha$ $=15^{\circ}$ (swirled air jet) and at ratio slit sizes $b / l=$ 0.1 (flat air jet); they are the lowest at angle of twisting plates $\alpha=90^{\circ}$ and at slit sizes ratio $b / l=$ 1.0 (compact air jet); their optimum value is $\alpha_{0}=$ $36^{\circ}$ (swirled air jet) and $b / l=0.35$ (rectangular air jet).

\section{DISCUSSION}

The presented results of the research of velocity attenuation, local resistance and noise level, as well as the optimization of design of air distributors for flat, compact, rectangular and swirled air jets are the basis for similar investigations of the other types of air streams and of the air distribution devices. Since the research was carried out only for the free isothermal air jets in the steady state, the results for compressed air jets in the both steady state and in the alternating mode would be interesting.

Author contributions: research concept and design, O.V.; Collection and/or assembly of data, O.V., N.S., I.C., O.D.; Data analysis and interpretation, I.S.; Writing the article, N.S., I.S., O.S., M.K., O.D.; Critical revision of the article, M.K.; Final approval of the article, M.K.

Declaration of competing interest: The authors declare that they have no known competing financial interests or personal relationships that could have appeared to influence the work reported in this paper.

\section{REFERENCES}

1. Abdulrazzaq AK, Plesz B, Bognar G. Enhanced thermal model for accurate pv module junction temperature estimation. 26th International Workshop on Thermal Investigations of ICs and Systems. Therminic 2020:9420496. https://doi.org/10.1109/THERMINIC49743.2020.942 0496.
2. Adamski M. Ventilation system with spiral recuperator. Energy and Buildings 2010; 42(5): $674-$ 677. https://doi.org/10.1016/j.enbuild.2009.11.005.

3. Andersson H, Cehlin M, Moshfegh B. Experimental and numerical investigations of a new ventilation supply device based on confluent jets. Building and Environment 2018;137:18-33.

https://doi.org/10.1016/j.buildenv.2018.03.038.

4. Basok BI, Davydenko BV, Farenuyk GG, Goncharuk SM. Computational Modeling of the Temperature Regime in a Room with a Two-Panel Radiator. Journal of Engineering Physics and Thermophysics 2014; 87(6): 1433-1437. https://doi.org/10.1007/s10891-014-1147-5.

5. Deshko V, Bilous I, Vynogradov-Saltykov V, Shovkaliuk $M$, Hetmanchuk $H$. Integrated approaches to determination of $\mathrm{CO}_{2}$ concentration and air rate exchange in educational institution. Rochnik Ochrona Srodowiska 2020; 22(1): 82 - 104.

6. Gorobets V, Trokhaniak V, Bohdan Y, Antypov I. Numerical Modeling of Heat Transfer and Hydrodynamics in Compact Shifted Arrangement Small Diameter Tube Bundles. Journal of Applied and Computational Mechanicsthis link is disabled 2021;7(1):292-301.

https://doi.org/10.22055/JACM.2020.31007.1855.

7. Gulay B, Sukholova I, Dzeryn O, Shepitchak V. Investigations of Compact Recuperators Acoustic Properties. Lecture Notes in Civil Engineering 2021; 127-133. https://doi.org/:10.1007/978-3-030-573409_16.

8. Hnativ R, Verbovskiy O. Distribution of local velocities in a circular pipe with accelerating fluid flow. Eastern-European Journal of Enterprise Technologies 2019; 2(7-98): 58 - 63. https://doi.org/10.15587/1729-4061.2019.162330.

9. Hulai B, Dovbush O, Piznak B, Kasynets M. Studying Equalization of the Radial Fans Discharge Flow. Lecture Notes in Civil Engineering 2020; 47: 119-126. https://doi.org/10.1007/978-3-030-27011$\underline{715}$.

10. Janbakhsh S, Moshfegh B. Experimental investigation of a ventilation system based on wall confluent jets. Building and Environment 2014; 80: 18-31. https://doi.org/10.1016/j.buildenv.2014.05.011.

11. Kapalo P, Klymenko H, Zhelykh V, Adamski M. Investigation of Indoor Air Quality in the Selected Ukraine Classroom - Case Study. Lecture Notes in Civil Engineering 2020; 47: 168-173. https://doi.org/10.1007/978-3-030-27011-7_21.

12. Kapalo P, Meciarova L, Vilcekova S, Burdova E, Domnita F, Bacotiu C., Peterfi K. Investigation of $\mathrm{CO}_{2}$ production depending on physical activity of students. International Journal of Environmental Health Research 2019; 29(1): 31 - 44. https://doi.org/10.1080/09603123.2018.1506570.

13. Kapalo P, Sedláková A, Košicanová D, Voznyak O, Lojkovics J, Siroczki P. Effect of ventilation on indoor environmental quality in buildings. The 9th International Conference "Environmental Engineering". Vilnius, Lithuania. Selected Papers 2014. https://doi.org/10.3846/enviro.2014.265.

14. Kapalo P, Vilceková S, Domnita F, Voznyak O. Determine a methodology for calculating the needed fresh air. The 9th International Conference "Environmental Engineering". Vilnius, Lithuania. Selected Papers. Section: Energy for Buildings 2014; 1-6. https://doi.org/10.3846/enviro.2014.264. 
15. Kapalo P, Vilceková S, Domnita F, Bacotiu C, Voznyak O. Determining the Ventilation Rate inside an Apartment House on the Basis of Measured Carbon Dioxide Concentrations. The 10-th International Conference "Environmental Engineering". Vilnius, Lithuania. 2017;30-35. https://doi.org/10.3846/enviro.2017.262.

16. Kapalo P, Vilcekova S, Voznyak O. Using experimental measurements, the concentrations of carbon dioxide for determining the intensity of ventilation in the rooms. Chemical Engineering Transactions 2014; 39: 1789-1794. https://doi.org/10.3303/CET1439299.

17. Kapalo P, Voznyak O, Yurkevych Yu, Myroniuk Kh, Sukholova I. Ensuring comfort microclimate in the classrooms under condition of the required air exchange. Eastern European Journal of Enterprise Technologies 2018; 5/10(95): 6 - 14. https://doi.org/10.15587/1729-4061.2018.143945.

18. Khovanskyi S, Pavlenko I, Pitel J, Mizakova J, Ochowiak M, Grechka I. Solving the coupled aerodynamic and thermal problem for modeling the air distribution devices with perforated plates. Energies 2019; $12(18)$ : 3488. https://doi.org/10.3390/en12183488.

19. Klymenko H, Labay V, Yaroslav V, Gensetskyi M. Criterial Equation for the Description of Low-Speed Air Distributor Operation. Lecture Notes in Civil Engineering 2020; 47: 235-242. https://doi.org/10.1007/978-3-030-27011-7 30.

20. Korbut V, Voznyak O, Myroniuk Kh, Sukholova I, Kapalo P. Examining a device for air distribution by the interaction of counter non-coaxial jets under alternating mode. Eastern European Journal of Enterprise Technologies 2017; 8(86): $30-38$. https://doi.org/10.15587/1729-4061.2017.96774.

21. Labay V, Dovbush O, Yaroslav V, Klymenko H. Mathematical modeling of a split-conditioner operation for evaluation of exergy efficiency of the R600A refrigerant application. Mathematical Modeling and Computing 2018; 5(2): 169-177. https://doi.org/10.23939/mmc2018.02.169.

22. Labay VY, Savchenko OO, Zhelykh VM, Kozak KR. Mathematical modelling of the heating process in a vortex tube at the gas distribution stations. Mathematical Modeling and Computing 2019; 6(2): 311-319. https://doi.org/10.23939/mmc2019.02.311.

23. Labay VY, Yaroslav VY, Dovbush OM, Tsizda AY. Mathematical modeling of an air split-conditioner heat pump operation for investigation its exergetic efficiency. Mathematical Modeling and Computing 2020; 7(1): 169-178. https://doi.org/ $10.23939 / \mathrm{mmc} 2020.01 .169$

24. Lis A, Spodyniuk N. The quality of the microclimate in educational buildings subjected to thermal modernization. E3S Web of Conferences 2019; 100: 00048. https://doi.org/10.1051/e3sconf/201910000048.

25. Lorin E. From structured data to evolution linear partial differential equations. Journal of Computational Physics 393 2019; 162-185. https://doi.org/10.1016/j.jcp.2019.04.049.

26. Mileikovskyi V. The macrostructure analysis of the turbulent mixing boundary layer between flows with the same or opposite direction. 9th International Conference on Environmental Engineering 2014; ICEE 2014. https://doi.org/10.3846/enviro.2014.273.

27. Snitynskyi V, Khirivskyi P, Hnativ I, Yakhno O, Machuga O, Hnativ R. Visualization of River Water
Flow in Hydrodynamically Active Areas under Different Flow Regimes. Journal of Ecological Engineering 2021; 22(9): 129-135. https://doi.org/10.12911/22998993/141385.

28. Shapoval S, Zhelykh V, Spodyniuk N, Dzeryn O, Gulai B. The effectiveness to use the distribution manifold in the construction of the solar wall for the conditions of circulation. Pollack periodica. An International Journal for Engineering and Information Sciences 2019; 14(2): 143 - 154 https://doi.org/10.1556/606.2019.14.2.13.

29. Spalart PR, Garbaruk AV. The Predictions of Common Turbulence Models in a Mature Vortex. Flow, Turbulence and Combustion 2019; 102: 667677. https://doi.org/10.1007/s10494-018-9983-6.

30. Spodyniuk N, Gulai B, Zhelykh V, Shapoval S. Leveling of pressure flow of radial ventilator in mine ventilation system. Naukovyi Visnyk Natsionalnoho Hirnychoho Universytetu 2019; 6: 80-86. https://doi.org/10.29202/nvngu/2019-6/12.

31. Spodyniuk N, Voznyak O, Sukholova I, Dovbush O, Kasynets M, Datsko O. Diagnosis of damage to the ventilation system. Diagnostyka 2021; 22 (3): 91-99. https://doi.org/10.29354/diag/141913.

32. Spodyniuk N, ZhelykhV, Dzeryn O. Combined Heating Systems of Premises For Breeding of Young Pigs And Poultry. FME Transactions 2018; 46: 651657. https://10.5937/fmet1804651S.

33. Tkachenko T, Mileikovskyi V. Increasing indoor air quality by a natural sanitizing interior. The $1^{\text {st }}$ JESSD Symposium: International Symposium of Earth, Energy. Environmental Science and Sustainable Development 02015 2020; 211: 1 - 8 . https://doi.org/10.1051/e3sconf/202021102015.

34. Trokhaniak VI, Rogovskii IL, Titova LL, Dziubata ZI, Luzan PH, Popyk PS. Using CFD Simulation to Investigate the Impact of Fresh air Valves on Poultry House Aerodynamics in Case of a Side Ventilation System. INMATEH - Agricultural Engineering 2020; 62(3): 155-164. https://doi.org/10.35633/INMATEH-62-16.

35. Voznyak O, Korbut V, Davydenko B, Sukholova I. Air distribution efficiency in a room by a two-flow device. Springer, Proceedings of CEE 2019. Advances in Resourse-saving Technologies and Materials in Civil and Environmental Engineering 2019; 47: 526-533. https://doi.org/10.1007/978-3030-27011-7_67.

36. Voznyak O, Myroniuk K, Sukholova I, Kapalo P. The impact of air flows on the environment. Springer, Proceedings of CEE 2019. Advances in Resoursesaving Technologies and Materials in Civil and Environmental Engineering 2019; 47: 534 - 540. https://doi.org/10.1007/978-3-030-27011-7_68.

37. Voznyak O, Spodyniuk N, Yurkevych Yu, Sukholova I, Dovbush O. Enhancing efficiency of air distribution by swirled-compact air jets in the mine using the heat utilizators. Naukovyi Visnyk Natsionalnoho Hirnychoho Universytetu 2020; $\begin{array}{llll}\text { 5(179): } & 89 & - & 94 .\end{array}$ https://doi.org/10.33271/nvngu/20205/089.

38. Voznyak O, Sukholova I, Myroniuk K. Research of device for air distribution with swirl and spread air jets at variable mode. Eastern European Journal of Enterprise Technologies 2015; 6/7(78): 15 - 23. https://doi.org/10.15587/1729-4061.2015.56235.

39. Voznyak O, Yurkevych Yu, Dovbush O, Serediuk Ya. The influence of chairs and passengers on air velocity in bus passenger compartment. Springer, 
Proceedings of CEE 2019. Advances in Resoursesaving Technologies and Materials in Civil and Environmental Engineering 2019; 47: 518 - 525. https://doi.org/10.1007/978-3-030-27011-7_66.

40. Xu J, Zhou S. Flow field analysis of trucks and a design of an additional drag reduction device. Engineering Review 2018; 38(1): 70-78.

41. Zhelykh V, Ulewicz M, Spodyniuk N, Shapoval S, Shepitchak V. Analysis of the processes of heat exchange on infrared heater surface. Diagnostyka 2016; 17(3): 81-85.

\section{Received 2021-10-22}

Accepted 2022-01-03

Available online 2022-01-11

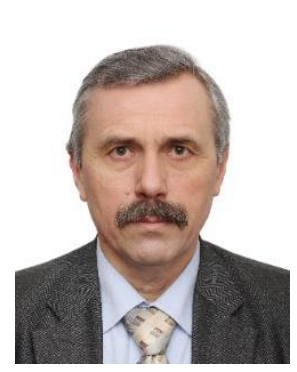

Orest VOZNYAK

Received his MSc (1983) in Building, PhD (1990), DSc (2018) in Technical Sciences. Currently, he is Professor in the Department of Heat and Gas Supply and Ventilation at Lviv Polytechnic National University, Ukraine.

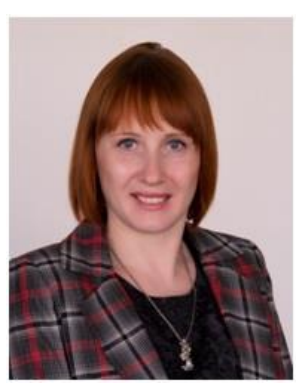

\section{Nadiia SPODYNIUK}

Received her MSc (2007) in Building, PhD (2011). Thesis: Energy efficient Heating provision of the poultry houses. Currently, she is Lecturer in the Department of Heat and Power Engineering at National University of Life and Environmental Sciences of Ukraine.

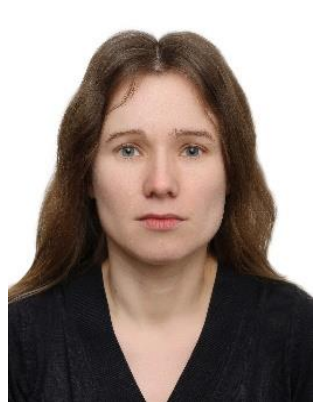

\section{IRYNA SUKHOLOVA}

Received her MSc (2007) in Building, PhD (2015). Thesis: Air distribution with swirl and spread air jets in variable regime in production apartments. Currently, she is Lecturer in the Department of Heat and Gas Supply and Ventilation at Lviv Polytechnic National University, Ukraine.

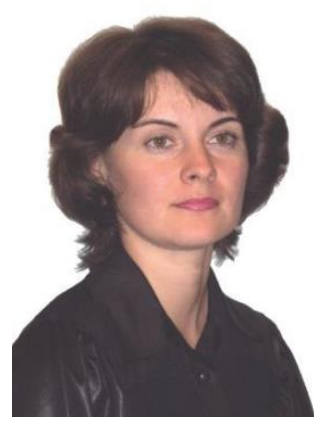

\section{OLENA SAVCHENKO}

Received her MSc (1999) in Heat and Gas Supply and Ventilation, PhD (2008). Thesis: Frictional heating of natural gas in the energy separator.

Currently, she is Associate Professor in the Department of Heat and Gas Supply and Ventilation at Lviv Polytechnic National

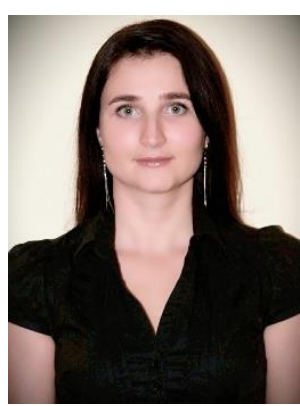

Mariana KASYNETS

Received her MSc (2009)

in Building, $\mathrm{PhD}$ (2013).

Thesis: Improvement of solar panels of periodic action that are combined with a cover of buildings. Currently, she is Lecturer in the Department of Heat and Gas Supply and Ventilation at Lviv Polytechnic National University, Ukraine.

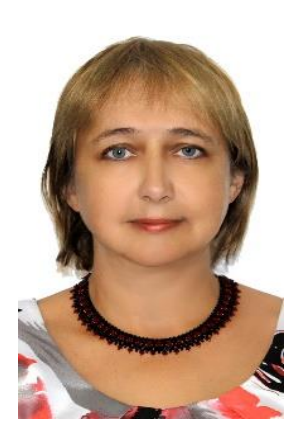

Oleksandra DATSKO

Received her MSc (1985) in Building, PhD (1994). Thesis: Improving the efficiency of solar heating systems by discrete orientation of solar collectors. Currently, she is Lecturer in the Department of Civil Safety at Lviv Polytechnic National University, Ukraine.

University, Ukraine. 